\title{
Organization
}

\section{Organizational Magic and the Making of Christmas: On Glamour, Grottos and Enchantment}

\begin{tabular}{|r|l|}
\hline Journal: & Organization \\
\hline Manuscript ID & ORG-17-0303.R3 \\
\hline Keywords: & Aesthetics, Atmospheres, Christmas, Magic, Sociomateriality, Glamour \\
\hline & $\begin{array}{l}\text { Drawing on qualitative research into the design, delivery and } \\
\text { organization of Christmas grottos this paper offers a critical } \\
\text { understanding of the role that a functional belief in organizational magic } \\
\text { plays in their manufacture and operation. Utilising classic anthropological } \\
\text { research into the cultural production of magical belief systems, I attend } \\
\text { to how such magic is produced through a network of sociomaterial } \\
\text { practices conducive to the commercial values of the Anglo-American } \\
\text { Christmas. I additionally draw on contemporary literature on aesthetic } \\
\text { and atmospheric organization in order to analyse the practical } \\
\text { accomplishment of organizational magic as a mode of captivation and re- } \\
\text { enchantment. The article concludes by emphasizing the increasingly } \\
\text { commercial utility of a functional belief in magic as an organizational } \\
\text { resource, highlighting the need for further empirical scrutiny, as well as } \\
\text { conceptual and theoretical analysis. }\end{array}$ \\
\hline & \\
\hline
\end{tabular}

\section{SCHOLARONE" Manuscripts}




\title{
Organizational Magic and the Making of Christmas: On Glamour, Grottos and Enchantment
}

\begin{abstract}
Drawing on qualitative research into the design, delivery and organization of Christmas grottos this paper offers a critical understanding of the role that a functional belief in organizational magic plays in their manufacture and operation. Utilising classic anthropological research into the cultural production of magical belief systems, I attend to how such magic is produced through a network of sociomaterial practices conducive to the commercial values of the AngloAmerican Christmas. I additionally draw on contemporary literature on aesthetic and atmospheric organization in order to analyse the practical accomplishment of organizational magic as a mode of captivation and re-enchantment. The article concludes by emphasizing the increasingly commercial utility of a functional belief in magic as an organizational resource, highlighting the need for further empirical scrutiny, as well as conceptual and theoretical analysis.
\end{abstract}

Keywords

Magic, Aesthetics, Atmospheres, Christmas, Glamour, Sociomateriality. 


\section{Introduction}

'Magic' is increasingly utilised as a yardstick against which organizational success is measured and even celebrated. Be it financial performance (Waters, 2012), the popularity of tourist destinations (Harrison, 2015), the job satisfaction of working for a particular company (CocaCola, 2018), or even the qualities of entrepreneurial risk takers (Ganzin, et al. 2019), magic signifies excellence, innovation and endeavour. More than this, however, it is also a medium through which organizational goals are pursued. It is an illocutionary (Austin, 1962) or performative act (Tambiah, 2013) that, when organized and managed, is believed to generate improved customer satisfaction, elevated employee engagement, and higher turnover and profitability. As Stivers (2004: 99) rightly credits it, magic creates a functional link between practice and outcome so that "magical practice is both responsible for the outcome and is its operational indicator'. Or, as Malinowski (2011) observed, magic is both instrumentally orientated towards achieving particular goals or outcomes while, at the same time, symbolizing established cultural beliefs in and through shared rituals and expression.

For magic to work in this way it cannot simply be asserted, however. Rather, it must reflect a shared consensus around both its existence and its capacity to affect the external world. This is generally brought about either by appealing to long-standing supernatural beliefs, as for example in respect of the role the constellations play in mitigating the indeterminacy of life (Adorno, 2001), or by creating new belief systems, such as the magical ability of consumption to overcome everyday existential challenges of meaning and identity (Elliot, 1997). Activities and interventions that set out to establish such new magical beliefs and conjunctions require, however, a performative dimension; one that demonstrates the necessary capacity to transcend the realm of 'make believe' and enter into the realm of what Schechner (2006: 42, emphasis added) describes as 'make belief', so that 'performances create the very social realities they enact'.

Yet despite the increasing presence of magic within the discourse of organization, it has remained a somewhat marginal interest within organization studies. Not that this should come as any great surprise. Organizations, and the science that has evolved to scrutinise them, both draw their legitimacy from the technical superiority of a disenchanted - or as Davies (2012: 46) would have it 'demagified' - world of reason and science (Weber, 2009). Nonetheless, as organizations became ever more engaged in the circulation of symbolic (Alvesson and Berg, 
1992), cultural (Parker, 2000), and increasingly aesthetic (Gagliardi, 1996; Strati, 1999) products, attention turned towards the ways in which such resources embodied if not an irrational, then certainly a pre-reflective approach to garnering organizational identification and, as a consequence, employee and consumer compliance. In this article, I consider magic and its production to be such an organizational product; one that has the capacity to draw people into a web of intentions and activities by appealing to a pre-reflective and, therefore, largely aesthetic or affective sensibility. Magic is considered to be both 'sympathetic' (Frazer, 2005) in that it directly influences people's feelings and behaviours, and 'atmospheric' (Böhme, 1993, 2017) in that it manifests itself in and through the production of resonant aesthetic conditions. In this sense, organizational magic is presented here as both a functional accomplishment and a potentially transcendent - if albeit manipulative - category of experience.

Exploring the conception and production of one such example of organizational magic, the magic of Christmas, I draw on research into the design, production and organization of Christmas grottos in order to unravel the ways in which this particular setting both symbolises, and mobilises magic as a medium of captivation, one directed towards producing appropriately seasonal subjectivities. By approaching the topic in this way, I seek to extend current research into organizational atmospherics within the context of what Böhme $(1993,2003)$ has described as an aesthetic economy. In particular, I directly report on the ambitions and understandings of those involved in the pursuit of atmospheric organization, and explore the practical manufacture of organizational magic as, in turn, an atmospheric phenomenon.

This is not, however, to conflate organizational magic with the category of atmosphere, although they certainly have much in common. They share a certain ineffability and irrationality - with both felt to exist and yet, at the same time, not to - presenting themselves as 'materiality without material' (Böhme, 2017: 146). Furthermore, to claim as I do, that the magic of Christmas needs to be understood primarily as an atmospheric phenomenon suggests at least some commonality in substance and the presence of a dialectical interdependence. Yet it is this same interdependence - the notion of a relationship between two identifiable qualities - that suggests they are also distinct.

Perhaps, on the simplest level, what distinguishes the atmospheric from the magical is the former's uniquely omnipresent character in that 'atmospheres imbue everything, they tinge the 
whole world or a view, they bathe everything in a certain light' (Böhme, 2017: 29). Magic, meanwhile, unless one is one of life's great unreflective celebrants is possibly less widespread, while even what for many is the mundane banality of everyday life has its own atmospheric qualities. More importantly, however, at least within the context I am discussing it here, unlike atmospheres, magic is always necessarily purposeful or performative. Understood as a largely onto-anthropological category of understanding (Mauss 2001, Frazer, 2005), magic is more than simply a way of experiencing or understanding the workings of the world, it is also necessarily an instrument by which one might influence it.

With this in mind, I begin below with a discussion of this onto-anthropological character of magic, while then briefly considering the relatively limited impact that it has had on the field of organization studies to date, taking what is ultimately a critical turn by drawing on Thrift's (2008) conception of glamour as a magical medium of aesthetic captivation. This leads me to the proposition that the primary medium of organizational magic, in this particular setting at least, is that of atmospheric management and that this itself can be understood as a sociomaterial process. Following a brief discussion of the methodological approach taken to the collection of qualitative data, I then identify several themes that emerged during the course of the research, most notably the atmospheric and sympathetic nature of the magic of Christmas and its broader implications for the critical interrogation of organizational practices that seek to captivate both employees, consumers and other stakeholders.

\section{The Origins and Meaning of Magic in Anthropology and Organization Studies}

So, what does it mean to speak of magic? While according to Styers (2013:258), there is little consensus on this due to its 'amorphous and shape shifting' nature, for twentieth century anthropologists such as Mauss (2001) and Malinowski (2011) magic, or more accurately a belief in magic, can be understood as a response to the negation of human desires by an external and hostile reality. More than simply a metaphor, therefore, from their perspective magic possesses an onto-anthropological quality that positions it as both a collective belief system that arises through associated rituals and practices, and an instrumental process of reality production that comes into being through the mobilisation of particular signs, actions, and indeed objects (Tambiah, 2013). 
Even earlier work by Frazer (2005), originally writing in 1889, argued that what contrasted magic to other ways of intervening in the world, especially science, was its sympathetic nature. By this, he referred to the efficacy of magical belief and practice that arose from the manipulation of images or artefacts that had either had previous contact as part of, or with the objects of their attention (for instance, a lock of hair), or that resemble or represent what they are believed to act upon (for example, a photograph). From this perspective, therefore, magic is defined less by what it 'is', and rather by what it is believed it can accomplish, alongside those material conditions of its possibility established both in and through what are often highly fetishized relationships between qualities or objects.

Returning to Mauss (2001), however, another important quality of magical belief that is relevant here is that which is deemed to be magical must also be socially recognised as such. So, while magical acts are predominately individual - commonly undertaken by a magician of some sort - it is the act's embeddedness within a wider cultural milieu of expectation and acceptance that bestows upon it its supernatural legitimacy. In other words, for an act to be 'magical' it must be recognized as such according to both historical and socio-cultural norms. For Malinowski (2011), in those societies where it is most widely practiced magic provides a medium of functional integration, one that inspires hope and promotes cooperation. Magic is, therefore, embedded within the collective beliefs and rituals of a culture whereby in reality the magician does 'nothing' themselves, 'or almost nothing, but makes everyone believe that he (sic) is doing everything' (Mauss, 2001: 175. More specifically

The art of the magician involves suggesting means, enlarging on the virtue of objects, anticipating effects and by these methods fully satisfying the desires and expectations which have been fostered by entire generations in common.

(Mauss, 2001: ibid emphasis added)

For Lévi-Strauss (1987: 64) magic is, therefore, a symbolic form of power, but one characterised by its capacity to 'take on any symbolic content whatever' by virtue of its ability to function as an empty or floating signifier. It is this malleability, or indeed indeterminacy, that allows magic to allow 'symbolic thinking to operate despite the contradiction inherent in it' (Lévi-Strauss, 1987: 63), an insight that is perhaps even more significant today when applied to circumstances or settings in which symbolism and sign systems have become a currency of 
reality (Baudrillard, 1982), and where affect has become a pervasive medium of social and economic discipline (Foucault, 1991).

Yet despite a long-standing interest within organization studies in say symbolism (Dandridge et al., 1980), magic is not a topic that has evoked a great deal of interest amongst even the more esoteric of writers in the field. For example, Burrell (1997) views magic as something largely associated with the pre-history of modern organization - albeit it one he is keen to revisit while Berg's (2008) short encyclopaedia entry on the subject simply identifies an affinity between several magical tropes and those organizational symbols and rituals that manifest themselves at times of say, organizational crisis. This is not to recognise that a range of concepts and practices that bear strong family resemblances to that of magic cannot be found across work in the field. Mysticism (Bartunek and Moch, 1994), totemism (Kamoche, 1995), spirituality (Zaidman et al., 2009), and even witchcraft (Clark and Salaman, 1996), have all been invoked - and occasionally conflated with magic, (see Ganzin et al., 2019) - in order to make sense of the ways in which organizations and their members act, especially when seeking to engage perceived stakeholders or negotiate indeterminacy or risk. Nonetheless, magic per se continues to remain a somewhat marginal concern.

In related fields such as consumer culture and marketing, however, magic appears more as a discursive touchstone when evaluating the practices and success of, for example, branding (Biel, 1997), advertising (Dégh and Vazsonyi, 1979), tourism (Cassinger and Eksell, 2017) and marketing (Brown, 2009). Indeed, Brown (2009) has gone as far as to entreat marketing managers to stop approaching their work as scientists, and to embrace the identity of 'magician' which, he claims, they already occupy by virtue of the similarities in many of their practices and beliefs. Even in the relatively dour world of mainstream managerial practice, when faced with organizational or environmental complexity managers are frequently urged to resort to what are often themselves quasi mystical terms such as 'strategy', 'governance' or 'leadership', that bear a striking resemblance to many a magical incantation by virtue of their abstraction and perceived efficacy in the real world (Schuyt and Schuij, 1998; Berg, 2003; Hill, 2017).

Nonetheless, to perhaps more fully appreciate the implications of magic as an organizational resource we should turn to the work of Thrift (2008) and his discussion of glamour. For Thrift (2008: 9), glamour and the growth of what he terms "“magical" technologies of public intimacy' have become a defining feature of contemporary organizational life. Presenting it as 
a form of 'secular magic', glamour is reclaimed by Thrift as both 'a [magical] spell which is both erudite and occult, but which can also encompass the nineteenth century meaning of "a deceptive or bewitching beauty or charm"” (Thrift, 2008: 14). Glamour functions, therefore, by virtue of an intensive intersection between 'aesthetic practices', the ingrained capacity of objects to "provide associations and conjunctions dissociations and echoes, that stimulate perception and imagination and, indeed, enjoyment' (Thrift, 2008: 11), and public intimacy; an outcome of the increasing pervasiveness of social media and its associated technologies. The objective of glamour within the commercial sphere at least, therefore, is an extension of 'captivation'; an organized seduction that draws the subject through affective identification and collective agreement, into a series of practices and networks - particularly through consumption - that can both aspire to and realize a magical promise of control over the world and one's self.

Certainly, what Thrift's work in particular reinforces is the significance of the intimate relationship between magic as both an instrumental and symbolic phenomenon, and the realm of aesthetic practices that both manifest and reproduce magic's cultural reach as a medium of consumer integration and discipline. With this in mind, the following section considers what it means to say that organizational magic requires a process of atmospheric production, and to examine how such atmospheres represent a profoundly aesthetic outcome of the sociomaterial organization of affect aimed at the reproduction of consuming subjects.

\section{On Aesthetics and Atmospheres}

Interestingly, the concept of an atmosphere when deployed outside of its natural-scientific context is already somewhat akin to magic in that it is sufficiently vague to be little more than an irritant to those schooled in more traditional ontologies (Griffero, 2014). Often considered 'airy and indefinite' (Böhme, 2013: 1) an atmosphere is not something that lends itself easily to precision of measurement or, once again, definition. Drawing on the work of both Böhme (1993, 2003, 2013, 2016, 2017), as well as those who have adapted his work in the realm of organization studies in particular (Borch, 2010; Hancock, 2011; Biehl-Missal, 2013; Julmi, 2016, 2017), however, an atmosphere is understood here as something that both induces and, at the same time, reflects affective experiences in the world. It is, to cite Griffero (2014: 5), that sense of being 'gripped by a something more', a something that we feel and respond to affectively; in doing so, we actively reproduce or negate it, unwittingly or not. 
In this sense, it is important to emphasize that precisely because of this, atmospheres are particularly amenable to production and manipulation. For while they are frequently generated in and through the mundane encounters between subjects and nature, throughout history much human ingenuity and energy has been expended in the conception, landscaping and building of spaces and places designed to generate and manage particular atmospheric conditions (Dale and Burrell, 2008).

Now, while Böhme (1993) has considered this quite extensively, especially in his discussions of an aesthetic economy (1993) or, more recently, through what he terms aesthetic capitalism (2016), in the broad field of management and organisation studies this understanding can perhaps be most readily traced back to two related strands of work. Firstly, in the area of retail and marketing research a concern with predominantly spatial, and particularly store design has long been evident (Kotler, 1973; Turley and Milliman, 2000). Secondly, within organization studies, earlier writing on the aestheticization of work organizations and management (Gagliardi, 1992; Strati, 1999) has also demonstrated a similar concern with the ways in which space and artefacts are landscaped and managed in such a way as to evoke organizationally sympathetic beliefs and behaviours. More recently, the latter has been especially influential as both an empirical and analytical resource in the aforementioned work of Borch (2010), Hancock (2011), Biehl-Missal (2013) and Julmi (2016), all of whom combine this work with insights from Böhme's earlier analysis of the aesthetic economy in order to engage critically with questions of how organizational atmospheres might be rendered instrumental in or through the performance of particular organisational subjectivities.

To avoid what Jumli (2017) considers a dualistic account of atmospheric production, however, whereby atmospheres are presented as simply managed through say the layout and aesthetics of organizational space and architecture, or the location of certain artefacts, atmospheres are understood here as an outcome of more sociomaterial practices relying upon a mutually constitutive interplay or 'entanglement' (Orlikowski, 2007: 1437) of the social and material realms of everyday life. As such, while profoundly material, atmospheric production and its management is considered a co-creation between a host of social and material agents and resources that not only interact, but which produce and reproduce each through a network of organizational intentions, actions and outcomes. As such, there is no 'social that is not also material, and no material that is not also social' (Orlikowski, 2007: 1437). 
While drawing on the above theoretical and conceptual resources, the empirical focus of this article is on how a particularly magical atmosphere - namely, the magic of Christmas - is manufactured sociomaterially, considering what role it plays in the production and propagation of particular organizational ambitions. For while, as Böhme (2017: 146) observes, 'the creation of atmospheres through the character of materials can indeed be called magic', Christmas is explored here as an example of an atmospheric phenomenon that relies almost uniquely on its characterisation as somehow magical; something that leaves the consumer and, as we shall see, very often the producer, 'bewitched' (Böhme, 2017: 146) by its ability to conjure up embodied experiences and memories that resonate not only with a desire, but a need to consume in the present.

\section{The Magic of Christmas}

Commercially speaking, no other season suggests the existence of 'magic' like the AngloAmerican Christmas (Miller, 1993). While local variations in how the season is celebrated continue to exist, it is the Anglo-American variant - characterised by unrivalled levels of production, consumption and employment (Connelly, 2000; Forbes, 2007; Hancock and Rehn, 2011) - that has emerged as globally dominant. Today the populations of more economically developed economies such as the UK, annually spend upwards of $£ 78$ billion during the holiday season $^{\mathrm{i}}$, while on the high street in particular, it can be a make or break period for retailers, with what is known as the 'golden quarter' - between $1^{\text {st }}$ October and $31^{\text {st }}$ December remaining crucial to the viability of many stores. It is also a time when a vast army of reserve labour is mobilised in order to meet consumer demand. Across the US, for example, over half a million seasonal positions are created each year, particularly in retail, hospitality and distribution ${ }^{\mathrm{ii}}$; while in the UK a similar proportion of jobs appear annually, albeit often low paid and both physically and emotionally demanding. Furthermore, in order to prosper in this seasonal marketplace businesses and other organizations increasingly depend not only upon their ability to attract consumers to their premises, and increasingly websites, but also to provide them with an enduring rationale for consuming - hopefully to excess - throughout the festive period.

Integral to this is a strategy of making Christmas commerce something special, something 'other' and 'sacred' (Bartunek and Do, 2011) compared to the normalcy of everyday life when temporal, financial and often emotional constraints place limits on our expenditure. It is this 
'other', this instrumental organization of the symbolic and affective that is extensively framed, and referred to here, as the magic of Christmas. This is an organizational magic that transforms the season into a time when the ordinary constraints of life are supplanted by a presentation of celebration of fantasy, glamour and the (re)enchantment of the everyday. Sociomaterial in character, the magic of Christmas emerges largely through staging opportunities for consumption as something communal and celebratory. Events such as the revealing of the Christmas windows in retail stores, or the switching on of the Christmas lights along predominantly commercial high streets have become highly anticipated events embodying, for many, the magical qualities of the season. Even the debut of Christmas television advertisements for retailers has now become a significant cultural event in many Christmas calendars ${ }^{\mathrm{iii}}$, opening the floodgates for a season of profligacy and consumer-oriented hedonism.

Not that the magic of Christmas is purely a fabrication of consumer capitalism. Mid-winter is a season that is long steeped in ancient magical beliefs and symbolism. What subsequently became a celebration of the messianic nativity was, from the outset, a time when magic, both beneficent and malevolent, inhabited the world (Miles, 1912; Hutton, 1996). The cold and dark, combined with the anticipated transitions of the approaching New Year, encouraged a belief in spiritual visitations by both Gods and long-dead ancestors who, during this time, could enter into communion with the living. Then as Christmas evolved, gradually supplanting its pagan origins, additional magical narratives emerged and began to also take hold, many of which over time came to have commercial connections. For instance, Saint Nicholas, or Santa Claus as he is now more widely known, although a figure ancient in origin, was globally popularised through his identification with Coca-Cola (McKay, 2008). Similarly, Rudolph the Red Nosed Reindeer, today the most popular of Santa's magical confidantes, started out life as a character in a department store Christmas give away (Marling, 2000).

Today, come autumn, the magic of Christmas manifests itself not only as a symbolic narrative that defines the possibilities and quasi-religious expectations of the season (Belk, 1987), but also as a bewitching, affective assault on the human sensorium. From the extensive promotion of Christmas films at the cinema and on multi-channel television (Connelly, 2000) through the, initially at least, uplifting Christmas music that plays in stores and shopping malls (JarmanIvens, 2008), to wall-to-wall Christmas advertisements (Twitchell, 1996) and even the appearance of public and domestic lights and decorations that reenchant those increasingly 
darkening and alienating streets and thoroughfares (Edensor and Millington, 2009), the magic of Christmas arrives in a profoundly aesthetic and atmospheric form.

And it is in this way that it arguably exercises its greatest impact and influence. By addressing the pre-intellectual and affective (Thrift, 2004) experiences and desires of those exposed to it, Christmas draws many of us into a web of intentionalities that identify achieving the magic of the season with the successful pursuit of a range of predominantly consumer activities. They contrive to produce what Williams (1977) refers to as particular 'structures of feeling'; structures grounded and contextualised in and though atmospheric relations of affect that suture together the demands of an aesthetic economy with individual expectations surrounding the season. Be it through the selling and buying of gifts, attending festive events, or simply downloading a festive film, the magic of Christmas is something that can be boxed, wrapped and taken home for all to share. Thus, we are faced with an almost normative imperative to 'eat, drink and be merry', one defined and made possible by the quality of the magic available to us. And it is through such a relationship that Christmas, in large part at least, retains both its resilience and hold on the popular imagination, despite the often-contradictory pressures and demands it also places upon all those who seem compelled to annually indulge it.

\section{Methods}

As I have intimated, the aim of this article is to examine how the magic of Christmas, as an example of organizational magic, is approached as a practical accomplishment, one brought into being through a process of atmospheric production and management. The magic of Christmas can be understood in respect of two overriding characteristics. Firstly, it is both symbolic in that it relies upon a collective agreement and belief in a series of widely held to cultural tropes (Mauss, 2001) - for example, the innocence of childhood - and instrumental, in that its power to enchant or captivate is based on its ability to foster a sympathetic identification (Frazer, 2005) between manufactured, but nonetheless idealized materialities, and their supposed efficacy in the 'real' world. Secondly, the magic of Christmas is both produced and experienced as a profoundly aesthetic and therefore atmospheric phenomenon; one conceived and operationalized in such a way as to draw the subject into a network of practices that serve not only to encourage work and consumption, but that also constitute an enduring (inter)subjective orientation to the reproduction of the season - a 'seasonal subjectivity' if you will. In order to explore such characteristics, this research utilised qualitative data and material 
concerned with the organization and management of a particular research setting - namely the Christmas grotto, that was collected as part of a larger project concerned with the organization of the festive season (Hancock and Rehn, 2011; Hancock, 2013; Hancock, 2016).

The original focus of this research concerned the labour process (Braverman, 1972) of performers working as Santa Claus and his associated assistants during the Christmas shopping period. As the project expanded, however, I increasingly needed to contextualise the work of these individuals within its wider sociomaterial setting and established institutional frameworks. During the initial stages of the study I recruited research participants utilising several approaches including: contacting theatrical agencies who were advertising vacancies for Santa Claus performers and their assistants at commercial rates; an advertisement in The Stage magazine and, increasingly, a snowballing process relying on word-of-mouth contacts and serendipitous encounters. Data was generated through a series of in-depth, semi-structured interviews from a purposive sample of individuals who had performed the role commercially at various points throughout their lives.

This initial sample consisted of 15 formal interviews, 14 of which were with male performers whose ages ranged from 52 to 81, and one female grotto assistant (who performed the character of an Elf), aged 32. All of the performers had worked exclusively in the UK, apart from one who had also worked in the US and a second who had worked exclusively in Finnish Lapland. The interviewees had performed across a range of locations including shopping malls, stores, at theme parks, private and corporate parties, at promotional events and in advertising, with their length of experience in the role ranging from one to over 20 years.

The interviews were underpinned by a predominantly phenomenological ontology concerned with understanding the lived experiences of those involved in the commercial performance of Christmas. This meant that, while cognizant of approaches to the exploration of aesthetic phenomena that draw upon more aesthetically sensitive epistemic frameworks (Hancock, 2005; Warren 2008), they were designed to explore the experiences of those individuals who chose to perform this particular role, and how they both experienced and managed its demands. Emergent from the original discussions and findings, I developed an increasing awareness of the perceived importance of the material resources to hand - including customers and clients and the socially constituted environments in which they worked, to achieving a believable performance as Santa Claus. Furthermore, it was the reiterated need to generate a 'magical 
atmosphere' that these performers appealed to in order to both articulate and often justify the nature of a successful performance that promoted my further inquiries into these issues.

Again, through a combination of word-of-mouth contacts and serendipitous meetings, the interview sample was extended to representatives of companies that provide and manage Christmas grottos and events, alongside employees at several retail outlets who oversee Christmas events at these facilities. In total, a further thirteen interviews were undertaken. These were with five senior managers and employees of two leading UK department stores, a combination of three owners and three managers at companies providing Christmas grottos, lighting displays and animations to stores and shopping malls across the UK, three UK shopping mall managers, the owner of a major UK Christmas theme park, and the owner/performer at the what at the time was the largest training centre and agency for Santa Claus performers in the country.

The research also involved a visit to the University of Lapland, Rovaniemi - where I met with the owner and employees of a major Finnish Christmas theme park - as well as a separate threeday period of observation and ethnographic interviewing at the 'Annual World Santa Claus Congress ${ }^{\text {'iv }}$ which is held in Bakken amusement park, Denmark, each July. These interviews, while continuing to explore the labour of seasonal performers, increasingly endeavored to understand the perceived objectives of these performances, the criteria for success and the conditions the interviewees, from their varying perspectives, believed were necessary for the successful performance of Christmas as a commercial and socio-cultural 'event'.

The formal and informal interview data was subject to an interpretative analytical approach drawing on the three-stage process of data reduction, data display and conclusion drawing described by Miles and Huberman (1994). This was subject to a process of open coding that allowed the data to be organized and then categorized in line with a combination of theoretically pre-indicated priorities. While these originally represented the emotional and aesthetic content of the work of the performers as the project developed in scope, my interest increasingly evolved into an exploration of the aforementioned theme; namely, the reproduction of an atmosphere conducive to the 'magic of Christmas' specifically generated at the site of Christmas grottos and their surrounding environments. This concerned not only the experiences of interviewees in respect of the conceptual parameters of 'the magic', and the role they played in creating it, but equally the mobilisation of those sociomaterial practices that, 
through an assemblage of material and human resources and actions, helped bring into being the desired atmospheric conditions and affective experiences.

In respect of the data presentation, given the diversity of the sources, individuals cited are not identified by either pseudonyms or individual labels, but are simply referred to in relation to either their position within an organization, or their occupational role.

\section{Magically Making Christmas}

In this section I want to consider how those involved in the design, delivery, organization, and management of Christmas grottos understand their role as producers of the magic of Christmas. As one might suspect, when dealing with a concept as seemingly indeterminate as magic Lévi-Strauss's (1987) 'floating signifier' - it is a concept that while on the one hand is central to how they articulate what they do, on the other it seems to fall victim to a condition of ineffability when it comes to formal interviews. Rather, it is to its aesthetic, or atmospheric qualities, that participants frequently refer, especially within the context of its purported ability to reconcile the commercial ambitions of their employing organization with the needs and desires of both Christmas consumers and employees.

A recurring theme in discussions with those involved in producing and managing grottos is a professed 'intangibility' of the process and the indeterminacy of success. 'Magic' is frequently evoked, therefore, as being both the process as well as the desired outcome of the preparations made for Christmas. As one manager of an events team at a leading London department store puts it when referring to his store's plans for Christmas, the grotto, and the impact they hoped it would have on both shoppers and staff (emphasis added):

There's something rather intangible about getting [it] right. Lots of time, money and hard work go into it, but at the end of the day it has to be, well, magical without being too... well, it's the atmosphere, isn't it?

While it should be stressed that at no point was it suggested by any of the interviewees that they possess any actual belief in magic as a supernatural force there is, nonetheless, a sense of awe expressed by many; particularly when discussing the apparently functional ability of 'magic' to encourage Christmas consumption. As a Director of Sales at the same department 
store put it (emphasis reported):

...it's the most magical that you can make Christmas and I think that's what the customers enjoy and that's when the customers buy - because they get that feeling of Christmas magic and if they get that within the department that they're buying from, they can take that magic home.

What is telling here is the way in which the aesthetic - the 'feeling of Christmas magic' - and the instrumental are visibly entwined in such a way that a functional belief in magic is discursively validated by virtue of its commercial utility. Furthermore, in order to sustain an atmosphere that is not only conducive to consumption at the point at which visitors to the store encounter it - namely the grotto - it is considered important that through the act of consumption and possession they are also able to transfer this into their own lives and homes for Christmas and hopefully beyond.

This aptly illustrates what was a frequently encountered sense that the magic of Christmas does indeed have the kind of sympathetic quality associated with a belief in magic by the likes of Frazer (2005). For, by coming into contact with the atmosphere of the grotto, visitors are presumed to be, to return to Thrift (2008), 'captivated' by the magic and would be inclined to want to take 'it home' where it might have a further and possibly greater and enduring impact. This relationship is particularly strengthened, of course, if customers actually buy something usually a souvenir or a gift from the Christmas Shop - but it is not necessary, as such captivation is considered a precursor to ongoing seasonal consumption.

Equally interesting, however, is the way in which my interviewees are almost able to locate themselves outside the vulgarities of commerce such that they cannot be held responsible for the propagation of what might otherwise be counted as the unreflexive, and potentially damaging excesses of consumption. As Styers (2103: 258) argues, magic has by virtue of its very indeterminacy, been deployed throughout history 'by various social agents to label their own practices, and in these situations those agents are often self-consciously positioning themselves as orthogonal to the dominant modes of social power'. And as so many of my interviewees stress, when it comes to Christmas, they are not simply salespeople or hucksters, but re-enchanters of the world. They deal in the 'sparkly and magical' and the 'pure magic of Christmas', whatever these terms might ultimately mean. 


\section{Building and Managing the Grottos}

Nonetheless, despite such apparent equivocation, what my participants quite clearly articulate is an acknowledgment that paying visitors have certain pre-established expectations about the nature and quality of 'the magic' they will encounter and how important it is, therefore, to 'get it right' and 'get the shoppers in'. As such, a significant emphasis is placed on ensuring that the material setting is sufficiently attuned with these more abstract notions of the magic at work. The utilisation of both traditional symbols and artefacts, such as 'twinkling lights', 'snow' and 'colourful decorations', as well as the landscaping of both the grotto and the surrounding environment through colour, texture, sound, and often smell, are viewed as foundational, generating a magical backdrop that visitors will return to year on year. One store designer, for example, describes the 'integrated vision' that is behind the store's seasonal theme, including the grotto, in the following terms:

So, window schemes and VM [visual merchandising] will demonstrate both traditional and future edginess through the use of materials, light and texture. They radiate magic, beauty, ethereal wonder and playfulness ...

Here a causal chain is evident, in the mind of the designer at least, one that exists between an assemblage of objects, words, practices, and also the visitors to the grotto (Tambiah, 2013) and what is an atmospheric encounter that, in turn, is characterised as magical, ethereal and playful. And while the sociomaterial landscaping of the overall grotto environment clearly plays a vital role in the atmospheric conditions associated with the grotto experience, even greater opportunities to reinforce this arise as visitors encounter the season's main icon and representative, Santa Claus.

Such grotto encounters generally require the further mobilisation of a rich sociomaterial repertoire in order to ensure that visitors experience the anticipated sense of other-worldliness and magic that they closely identify with the character; a repertoire that helps them to suspend any disbelief they might have regarding his role within the seasonal narrative. At the most immediate level, this includes a combination of material landscaping and process management that grounds the desired atmosphere or, at the very least, mitigates against anything that might detract from it. Costing on average anywhere between $£ 20,000$ and $£ 150,000$, such grottos commonly feature not only the previously alluded to high standards of design, lighting and 
decoration, but also the elaborate use of animatronic features - such as singing and dancing characters, most obviously 'elves and reindeer' - and increasingly three-dimensional or holographic projections and movies designed to bring the 'Christmas magic to life'.

Described by one grotto manager as 'a parental apparatus to achieve the feeling of giving their children Christmas', such grottos are understood as serving two primary functions in the process of atmospheric production. Firstly, they offer a sociomaterial experience that entwines the human performance of the Santa Claus role with the materiality of the resources afforded by the grotto design itself. As one performer explains it (emphasis added):

It's got to be magical; it's got be an experience and they've got to believe you are Santa. I'm $60 \%$ and the grotto's $40 \%$ of it. It's got to look good... magical.

This ' $40 \%$ ' is itself frequently assembled from a combination of resources drawn from the realm of contemporary technology - such as the aforementioned lighting and animatronics alongside bodies, imagery and artefacts traditionally associated with those narratives that circulate in respect of the magical home of Santa Claus as described here by another performer when recalling his first day on the job (emphasis added):

When you approached, [the grotto] it had old snow shoes outside and reindeer harness hanging on the wall and you could see through the little window inside and there was an electric log stove and... oh, a beautiful log interior and Father Christmas sat on this bench with his big sacks of things and things all over the wall and a Christmas tree.

Secondly, however, the grotto also plays a central role in incorporating the materiality of bodies, and the affective responses of visitors and consumers, into the reproduction of the atmosphere itself. As previously argued, atmospheres are more than simply the product of spatial landscaping and the subsequent placement of a series of, albeit significant, artefacts. They are also produced and reproduced through an ongoing entanglement of the social and material, the behavioural and the affective, that seek to generate particular ways of feeling and being. In order to sustain the magical Christmas atmosphere, designers have also to be observant, therefore, of the ways in which bodies and their 'spatial practices' (Lefebvre, 1991) engender particular affective states which might themselves be experienced as, or as not, magical. 
As such the grotto also functions to ensure, for instance, that the practical and often tiresome act of queuing to meet the performers becomes integral to the atmospheric context of the encounter and the Christmas environment as a whole. Embodied moods and behaviours are marshalled, therefore, to sustain the magic by distracting and engaging visitors - especially restless children and their frustrated parents - throughout their visit. As one manager of a Christmas grotto company observes:

What's really important is making sure we keep the visitors feeling as Christmassy as possible. You can have the best grotto in the world, but if everybody is frustrated and miserable then it's not gonna' be very magical, is it?

Furthermore, the sociomaterial organization of even the most mundane operations of the grottos is approached in such a way as to attenuate any possible distraction from the magic including, for example, basic ergonomic requirements surrounding ventilation and flowthrough, and the quick and unobtrusive removal or rectification of non-magical distractions such as litter and breakages. Equally, as one grotto designer notes, 'you need a certain size operationally, to have a distance between the queuing public and the Santa visit. You don't want to feel that everyone is looking at you while you are with Santa.' Where multiple performers are operating, such matters are of even greater concern and attention, as the same designer also notes:

The layout of the experience is all pretty much geared up around the kids not knowing there's, say, four Santas, and yet there's four doors and they all go in at the same time and they all come out the back at the same time.

While the importance of resources such as lighting, seasonal artefacts, and even the staging of the bodies and affective expressions of visitors themselves all indicate how the sociomateriality of these grottos is geared towards experiences and practices that reproduce the magic of Christmas it does not stop there, however. Increasingly, computer systems are also being incorporated in such a way as to directly enhance the magical experience of the grotto visit. The increasing use of an online booking system associated with many Christmas events, for example, is particularly appealing to commercial operators not only due to its ability to collect targeted marketing data but also by virtue of the way information is gathered at the point of 
booking. The latter can engender encounters that enhance the magical experience. As one grotto manager who was also a parent told me:

My daughter's ten, and she doesn't believe anymore. She hadn't been anywhere where they do this [online booking] before. So, she goes in with her younger brother quite reluctantly and [Santa says] 'Oh William and Alice, how's your cat Tufty?' And she just turned to me and said, 'How does he know?' It was something really special and magical. It managed to re-spark that bit of belief.

\section{Sociomaterial Performances of Santa Claus}

As the above extract suggests then, some of the starkest instances of the technical orchestration of magic-making take place during direct encounters between visitors and the Santa Claus performers within the grottos. It is here that the individual performers strive to directly and meticulously reproduce the magic in and through their own embodied performances - how they speak, look and listen for example - as well as through their interactions with, and manipulation of, props or artefacts that reproduce the conditions under which such actions are, in the magical sense, considered efficacious. Such practices then elicit particular affective responses aligned with the magic of Christmas, such as awe and wonder. Take for example the use of 'magic keys', as one performer describes it (emphasis added):

I've a magic Santa key, which I found in a little market... The part that goes into the lock was never cut, so it's just literally unshaped metal and it looks... It was quite old and rusty, and the story on that one if the kids ask... You know, sometimes they get worried if they haven't got a chimney, so you show them that and I say, 'That magically goes into any lock in the world and that's why there's no shape to it'.

Here, the entanglement of employee performance and the creative reappropriation of the materiality of the artefact - 'It was quite old and rusty' - within the context of a narrative that sustains the magical atmosphere of the overall experience illustrates a pivotal organizational moment. It is one that reproduces both the symbolism of the character through the performativity of the resources to hand - words, objects and practices - as well as the instrumental value of the encounter for both the paying visitor and the service provider. 
Being magical, however, and therefore external to the mundane demands of the physical laws of nature, also results in a number of occasions when an absence of certain material resources underpins, if not heightens, the efficacy of such magical encounters. Take as an illustration the impact the absence of glass from one performer's spectacles has:

\begin{abstract}
A lot of times suits come with glasses that have no glass in them and kids will pick up on that and they'll say, you know, "How come your glasses have no glass in?" You say, "Well they're magic glasses".
\end{abstract}

While spectacles are implicitly identifiable as a valuable artefact in the performance of Santa Claus, even a material absence - in this case that of glass - is mobilised in and through the belief and inquisitiveness of the child in order to establish a sociomaterial entanglement that ensures the magical atmosphere of the encounter is sustained. Glasses with glass are authentic, glasses without glass are magical; made so through a narrative endowing them with a capacity to act upon the world in ways that, outside the magic of Christmas which the artefact and act also sustains, is impossible.

Even outside of the grotto environment many of the performers, particularly those who sport real beards when out of costume, spoke of a felt need to sustain the magic throughout the year if questioned or engaged with by children. While often an extension of the demand for a high degree of emotional labour associated with performing the role, once again the extension of this performative identity - i.e. Santa Claus - is only made possible by their ability to appeal both to an embodied materiality - usually the presence of the beard - and the presence or indeed absence of magical artefacts and the social interactions they bring into being. This was emphasised by one particularly experienced performer who recounts how:

\footnotetext{
Whenever I see a kid, you know, and I know that the kid is talking about me - you know, "That's Santa!" - I deliberately go over to them and, not saying anything to their parents, I just talk to the child and say... "I'm only here early because I'm just checking is everybody nice. I've got my magic book with me. Can you see the book?' They say no. I say "Well, it's a magic book".
}

It would be wrong to identify this form of sociomaterial activity solely with the performers directly employed to deliver it and those adults and children who consume it, however. The 
kinds of grottos discussed above are exclusively located in commercial settings and, as such, participants in the study stress that despite other pressures throughout the Christmas period all employees are expected to make a contribution to generating the magic of Christmas for both customers and other staff alike. As such, other employees are also often expected to undertake the requisite emotional and aesthetic labour (Hochschild, 1985; Witz et al., 2003) when interacting with both visitors and other employees in order to reproduce both the symbolism of the season and its magical atmosphere. As one shopping centre manager is quick to explain:

\footnotetext{
Well, it's about getting everybody to pitch in, to getting the Christmas buzz about the place. Once the lights are up, the music is going, and everybody is dressed up, it really is a great atmosphere. The shoppers love it.
}

Similar views are expressed by other managers and employees, especially those working in the larger department stores. Here, the crafting of the atmospheric backdrop to Christmas consumption is realized not just through the juxtapositioning of 'lights', 'smells' and 'decs', but also through the 'buzz' and 'electricity' that these purposively pursued entanglements aim to create in and through the bodies of all those working and consuming throughout the stores. This is the magic at work.

\section{Discussion}

We do not, despite Weber's (2009) predictions, live in a wholly disenchanted world. In part, this is a consequence of the emergence of an aestheticized economy (Böhme, 1993) that thrives on the reimagining and staging of a host of new sounds, sights and even smells that seduce the individual and re-enchant the world - that takes 'make belief' and seeks to transform it into 'make believe' (Schechner, 2006). Yet this is not a re-enchantment for its own sake, or even for that of spiritual salvation. Rather it is one with, if not an albeit singular then a primary objective: the organization and 'escalation of consumption' (Böhme, 2017: 11).

When it comes to Christmas, of course, criticisms of the overly commercial nature of what is ostensibly a religious festival have come and gone for at least the last two hundred years or so and, if one wishes, can be traced back notably further (Miles, 1912). Today, however, there may well be far more rigorous empirical grounds for concern rather than simply a distaste for ‘crass materialism' (Miller, 1993: 134). Increasingly, Christmas has been identified with a host of global social and environmental ills including its contribution to environmental despoliation 
and a culture of waste (McGuire, 2016; Sheffield, 2016), a rise in unsustainable personal debt (Wood, 2017; Dickler, 2018), exploitative working conditions (Chaberlain, 2016), an annual increase in personal tragedies such as an increased sense of social exclusion (Saloen, 2016) and domestic violence (Oppenheim, 2015), and even the destruction of economic value itself (Waldfogel, 2009).

Furthermore, as the demands Christmas places on individuals have intensified, so has there grown a festive industry in its own right, providing advice and services attuned to helping us to 'get through the holidays', while consuming more resources in order to do so (Hancock and Rehn, 2011). And this burden of organizing Christmas, particularly at home, has a distinctly gendered impact with the demands of the season in terms of not only gift selection and buying (Fischer and Arnold, 1990) falling disproportionally on women, for example, but also with women being expected to be subservient to the task of creating the perfect magical experience (Brewis and Warren, 2011, Freemen and Bell, 2013). Combine this with what are the unavoidable observations about the highly patriarchal (however benign) role played by Santa Claus himself in the seasonal story, and it is readily apparent that there is much to be concerned about.

When considered in this way, therefore, the magic of Christmas might appear to be little more than yet another ideological spur of what Marcuse (1988) once referred to as the performance principle; an orchestrated belief that in order to truly feel the magic of the season one must work to 'perform' the consumer experience and all that it requires and offers. As such, this organizational magic represents what is perhaps simply an amenable technology justified, in this instance, by a range of new and pre-existing culturally embedded values; values that identify this mid-winter festival and its instrumental capacity to entwine consumption with a magical celebration of generosity and the possibilities encapsulated in youthful innocence and imagination. Indeed, from this perspective Christmas is not only magical, it is truly glamorous in its capacity to bewitch and seduce through its portrayal of a unique time that legitimatises special indulgences and a message that to deny these would break a spell from which whatever its hidden, or not so hidden global and personal costs - so much collective enjoyment is purportedly garnered. In doing so, the promise of a magical experience is invoked as identical with the performance of what is an increasingly disciplined seasonal subjectivity; one that both reproduces and consumes seasonal 'magic' as a means of 'getting into the spirit' while 
contributing, without reflection, to those ills of Christmas - ranging from environmental despoliation to the perpetuation of gender inequalities - that I have alluded to above.

But what of the voices and lived experiences of those charged with delivering the magic, or at least those sociomaterial conditions within which it might thrive? Well, there is certainly no suggestion of any real resistance to, or even discomfort with, what is taking place and the role my interviewees play in it. The majority of these 'modern practitioners of magic' (Styers, 2013: 255 ) be it grotto designers, managers, or performers, appear not only to relate to what they are doing as somehow magical, they actively embrace a functional belief in their creative identities as 'magicians'. They are enthralled, to reinvoke Mauss (2001: 175), by their responsibility to enlarge 'the virtue of objects' and satisfy 'desires and expectations' with enthusiasm. Indeed, as I suggested above, this organizational magic in actual fact manifests itself as a way in which they seem to insulate themselves from any incursion of reflexivity or indeed sense of responsibility for anything other than bringing the joy of magic back into the world. This was something that is aptly illustrated by the reply of one employee charged with a store's decorations, when asked what the most enjoyable thing about the job is:

The buzz that your Christmas Hall downstairs is packed, and people are enjoying what they're buying, their faces are changing...

As such, charges of aesthetic manipulation or the imposition of a narrowly conceived seasonal subjectivity simplify what is viewed by many participants as an essentially benevolent process that while functional - in that it 'works' - actually, in their view at least, transcends any accusation of instrumentality that might be associated with their sorcery by virtue of the enrapture they believe is on offer.

Of course, while as Thrift (2008: 21) observes, not everybody is 'taken in' by the glamour, the enchantment or the magic. Certainly not everyone believes Christmas to be the most magical time of the year, or that the ability to order take-away food via a smartphone app ${ }^{v}$ makes them Harry Potter. Yet as we inhabit a world in which a functional belief in magic increasingly manifests itself as a pervasive form of organizational currency - demanded of employees, sold to customers, and exchanged for reality - the capacity of such beliefs to penetrate the ways in which organizations represent their activities and commodify and discipline their products and people is a cause for guarded concern. As I have argued, a defining feature of magic is that it 
is both self-confirmatory - providing, as Stivers (2004) noted, the quality of both its means and its outcomes - as well as contradictory. The latter is due to the fact that while it offers the user the promise of control over the world, or even of enhancing one's life and that of others, by virtue of its very practice, it simultaneously restrains and restricts those opportunities as a result of its spellbinding capacity to enchant. Yet such spells cannot easily be broken without denying one's own sociality and identity within the milieu that collectively accepts the grounds of their legitimacy, or the hope, as in this instance, for the enchantment and perhaps redemption they offer.

And it is this that perhaps pushes magic beyond just another example of the aesthetic manipulation of our hopes and desires, one that frequently underpins capitalist economic exchange (Biehl-Missal and Saren, 2012). Rather the production - and experience - of organizational magic constitutes a process whereby what Phelan (1993: 147) might claim to be an interactive aesthetic of presence is created through 'the interaction between the object and the spectator'. That is, one that continues and in turn reproduces, particular structures of feeling - despite the immediate absence of the 'magic' - in order to organize consumption practices, practices that are themselves conducive to the reproduction of a re-enchanted regime of socioeconomic life and belief. This both relies, therefore, on a resilient and recurring network of collective mythologies and agreements and, in doing so, reproduces them through a pattern of performances and restricted subjectivities that are, by virtue of their aesthetic ontology, prereflective (Welsch, 1997). This combination of aesthetics and affectivity is powerful in its conception and effects, not in spite of, but precisely because it goes beyond mere manipulation; its potency derives from magic's capacity as a medium of captivation, one that is simultaneous to what it produces: an amorphous, ineffable, and possibly absent, but nonetheless magically seductive atmosphere.

\section{Conclusion}

In this article I have considered what is a single, but nonetheless economically significant, example of re-enchantment as it is materialized, perceived and experienced through the atmospheric mobilisation of organizational magic - and specifically the magic of Christmas as a mode of, to use Thrift's (2008) terminology, captivation. Drawing on data derived from a ten-year study of Christmas as an organizational phenomenon, I have argued that in order to fully grasp the means by which such a powerful medium of organizational engagement might 
be both manufactured and staged, one can best understand it as atmospheric in nature. It is generated and managed through the intermeshing or entangling of both an object materiality that frames the spaces within which our experiences take place, alongside the embodied and affective responses of those who inhabit them.

In the discussion above, I have illustrated this with reference to the affective labour undertaken by Santa Claus performers, those consumers - both young and old - who visit them, and the conception, design and management of the grottos and surrounding environments in which they meet, demonstrating how the intermeshing or entangling of the social and the material across these dimensions of the production of organizational magic, is not a random or purely emergent process. Rather, I have explored how it is the consequence of an organizational intentionality that seeks to shape and manage an atmosphere of feeling, or 'tonality' (Böhme, 2016:86), that accepts what is, in effect, a commercial setting as something that purportedly transcends the instrumentality, and indeed vulgarity, of commerce; something imbued with a sense of otherworldly and specifically seasonal content which, in this instance, defines the magic of Christmas. While perpetually vulnerable to commercialism this magic is believed by those involved to somehow go beyond it; to reproduce what Böhme (2016) and others have referred to as a 'something more', or in Thrift's terms, a mode of 'captivation'. The extent to which this practical accomplishment of magic - as a mode of organizational captivation or reenchantment - is conducive to the reproduction of a contemporary festival highlights the cultural significance of the magical as an organizational phenomenon, one that requires further empirical scrutiny, as well as conceptual and theoretical analysis of its production and consumption. 


\section{References}

Adorno, T. (2001) The Stars Down to Earth and Other Essays. London: Routledge.

Alvesson, M. and Berg, P.O. (1992) Corporate Culture and Organizational Symbolism.

Berlin: de Gruyter.

Austin, J. (1962) How To Do Things with Words. Oxford: Oxford University Press.

Bartunek, J.M. and Do, B. (2011) 'The Sacralization of Christmas Commerce'. Organization. 18, pp.795-806.

Bartunek, J. \& Moch, M. (1994). 'Third-order Organizational Change and the Western Mystical Tradition'. Journal of Organizational Change Management. 7, pp. 24-41.

Baudrillard, J. (1982) [1972] For a Critique of the Political Economy of the Sign. St Louis, MI: Telos.

Belk, R. (1987) 'A Child's Christmas in America: Santa Claus as Deity, Consumption as Religion', The Journal of American Culture 10, pp. 87-100

Berg, P. O. (2003) "Magic in Action: Strategic Management in a New Economy." In, B.

Czarniawska \& G. Sevón (eds) The Northern Lights: Organization Theory in Scandinavia, Malmö: Liber, pp. 291-315.

Berg P.O. (2008) 'Magic in Organizing'. In, S. Clegg, and J. Bailey (eds), International Encyclopedia of Organization Studies, London: Sage, pp. 838-842.

Biel, A. (1997). 'Discovering Brand Magic: The Hardness of the Softer Side of Branding'. International Journal of Advertising, 16 pp. 199-210.

Biehl-Missal, B. (2013). 'The Atmosphere of the Image: An Aesthetic Concept for Visual Analysis', Consumption Markets \& Culture, 16, pp. 356-367.

Böhme, G. (1993). 'Atmosphere as the Fundamental Concept of a New Aesthetics', Thesis Eleven, 36, pp. 113-126.

Böhme, G. (2003). 'Contribution to the Critique of the Aesthetic Economy', Thesis Eleven, 73, pp. 71-82.

Böhme, G. (2013) 'The Art of the Stage Set as a Paradigm for an Aesthetics of Atmospheres, Ambiances, 315, pp. 1-18.

Böhme, G. (2016). Critique of Aesthetic Capitalism. Berlin: Mimesis International.

Böhme, G. (2017). The Aesthetics of Atmospheres [ed. J.-P. Thibaud]. London: Routledge.

Borch, C. (2010). 'Organizational Atmospheres: Foam, Affect and Architecture', Organization, 17, pp. 223-241.

Braverman, H. 1974. Labor and Monopoly Capital. New York: Monthly Review. 
Brewis, J. and Warren, S. (2011) 'Have Yourself a Merry Little Christmas? Organizing Christmas in Women's Magazines Past and Present'. Organization, 18, pp.747-762. Brown, S. (2009). 'Double, Double Toil and Trouble: On the Equivocal Magic of Marketing'. Journal of Customer Behaviour, 8 pp, 163-175.

Burrell, G. (1997) Pandemonium. London: Sage.

Cassinger, C. and Eksell, J. (2017) 'The Magic of Place Branding: Regional Brand Identity in Transition', Journal of Place Management and Development, 10, pp. 202-

212.Chamberlain, G. (2016) 'The Grim Truth of Chinese Factories Producing the West's Christmas Toys', The Observer, December $4^{\text {th }}$.

Clark, T. and Salaman, G. (1996) 'The Management Guru as Organizational Witchdoctor'. Organization, 3, pp. 85-107.

Coca-Cola Company (2018) 'Why Work at the Coca-Cola Company?', https://www.coca-colacompany.com/careers/why-work-at-the-coca-cola-company.

Connelly, M., ed. (2000). Christmas at the Movies. London: I.B. Tauris.

Dahl, R. (1964) Charlie and the Chocolate Factory. London: Allen and Unwin.

Dale, K. (2005). 'Building a Social Materiality: Spatial and Embodied Politics in Organizational Control', Organization, 12, pp. 649-678.

Dandridge, T., Mitroff, I. and W. Joyce, (1980) 'Organizational Symbolism: A Topic to Expand Organizational Analysis'. The Academy of Management Review 5, pp. 77-82. Davies, O. (2012) Magic: A Very Short Introduction. Oxford: Oxford University Press. Dégh, L., \& Vazsonyi, A. (1979). 'Magic for Sale: Märchen and Legend in TV Advertising'. Fabula, 20, pp. 47-68.

Dickler, J. (2018) 'Holiday Hangover: Americans Racked Up More Than \$1,000 Each in Holiday Debt' Tuesday, January $2^{\text {nd }}$.

https://www.cnbc.com/2018/01/02/americans-racked-up-more-than-1000-in-holidaydebt.html.

Edensor, T. and Millington, S. (2009) 'Illuminations, Class Identities and the Contested Landscapes of Christmas', Sociology, 43, pp. 103-121.

Elliott, R. (1997) 'Existential Consumption and Irrational Desire'. European Journal of Marketing, 31, pp. 285-296.

Fischer, E. and Arnold, S.J. (1990) 'More Than a Labor of Love: Gender Roles and Christmas Gift Shopping'. Journal of Consumer Research, 3, pp. 333 - 345. Flanders, J. (2017) Christmas: A Biography. London: Picador. 
Forbes, B. D. (2007). Christmas: A Candid History. Los Angeles, CA: University of California Press.

Fotaki, M., Kenny, K. and Vachhani, S. (2017) 'Thinking Critically About Affect in Organization Studies: Why It Matters'. Organization, 24, pp. 3 - 17.

Foucault, M. (1991) Discipline and Punish. Harmondsworth: Penguin.

Freeman, L. and Bell, S. (2013) 'Women's Magazines as Facilitators of Christmas Rituals'

Qualitative Market Research: An International Journal, 16, pp. 336-354.

Frazer, J.G. (2005) The Golden Bough. Waldorf, ML: Cosmo Publishers.

Gagliardi, P., ed. (1992). Symbols and Artifacts. Berlin: de Gruyter.

Gagliardi, P. (1996) 'Exploring the Aesthetic Side of Organizational Life, in S. Clegg, C. Hardy and W. Nord (eds.) Handbook of Organization Studies. London: Sage, pp: 565 580.

Gell, A. (1992). 'The Enchantment of Technology and the Technology of Enchantment'. In J. Coote and A. Shelton (eds), Anthropology, Art and Aesthetics. Oxford: Oxford University Press, pp. 40-63.

Ganzin, M., Islam, G. and Suddaby, R. (2019) 'Spirituality and Entrepreneurship: The Role of Magical Thinking in Future-Oriented Sensemaking', Organization Studies. https://doi.org/10.1177/0170840618819035

Griffero, T. (2014) Atmospheres. Abingdon: Routledge.

Hancock, P., (2005) 'Uncovering the Semiotic in Organizational Aesthetics'. Organization. 12, pp, 29-50.

Hancock, P. (2011). 'Organizational Change: The Aesthetic Dimension'. In D. Boje, B. Burnes, B. and J. Hassard (eds) The Routledge Companion to Organizational Change. London: Routledge, pp. 521 - 534.

Hancock, P. and A. Rehn (2011). 'Organizing Christmas', Organization, 18, pp. 737-745. Hancock, P. (2013) “"Being Santa Claus”: the pursuit of recognition in interactive service work'. Work, Employment \& Society, 27, pp.1004-1020.

Hancock, P. (2016) 'A Christmas Carol: A Reflection on Organization, Society, and the Socioeconomics of the Festive Season'. Academy of Management Review, 41, pp.755765.

Harrison, M. (2015) '32 Magical Destinations to Visit in This Lifetime’, BuzzFeed, https://www.buzzfeed.com/melissaharrison/magical-traveldestinations?utm_term=.pjraWpoq\#.yw2OBRkXg. 
Hill, A. (2017) 'The Magical Thinking That Misleads Managers'. Financial Times, November $27^{\text {th }}$.

Hochschild, A.R. (1983) The Managed Heart. Berkeley, CA: University of California Press. Hutton, R. (1996). The Stations of the Sun. Oxford: Oxford University Press.

Jarman- Ivens, F. (2008) 'The Musical Underbelly of Christmas'. In S. Whiteley (ed.), Christmas, Ideology and Popular Culture, Edinburgh: Edinburgh University Press, pp. 113-34.

Julmi, C. (2016). 'The Concept of Atmosphere in Management and Organization Studies', Organizational Aesthetics, 6, pp. 4-30.

Julmi, C. (2017) Situations and Atmospheres in Organizations: A (New) Phenomenology of Being-In-The-Organization. Berlin: Mimesis International.

Kamoche, K. (1995) 'Rhetoric, Ritualism, and Totemism in Human Resource Management', Human Relations, 48, pp. 367-385.

Kotler, P.1973, 'Atmospherics as a Marketing Tool'. Journal of Retailing 49, pp. 48-64.

Lefebvre, H. (1991). The Production of Space. Oxford: Blackwell.

Lévi-Strauss, C. (1987) Introduction to the Work of Marcel Mauss. London: Routledge.

McGuire, P. (2016) 'The Ghost of Christmas Waste: Consider the Impact of Those Gifts'. The Irish Times, December $15^{\text {th }}$.

McKay, G. (2008) 'Consumption, Coca-colonisataion, Cultural Resistance and Santa Claus' in S. Whiteley (ed.), Christmas, Ideology and Popular Culture. Edinburgh: Edinburgh University Press. Pp. 50-67.

Malinowski, B. (2011) Magic, Science, Religion and Other Essays. London: Souvenir Press. Marcuse, H. (1998) Eros and Civilization. London: Routledge.

Marling, K. A. (2000) Merry Christmas. Cambridge, MA: Harvard University Press.

Mauss, M. (2001) A General Theory of Magic. London: Routledge.

Miles, C. A. (1912) Christmas in Ritual and Tradition, Christian and Pagan. London: T. Fisher Unwin.

Miles, M. B. and A. M. Huberman (1994). Qualitative Data Analysis (2nd edition). Thousand Oaks, CA: Sage Publications.

Miller, D. (1993) 'A Theory of Christmas'. In D. Miller (ed.), Unwrapping Christmas, Oxford: Oxford University Press, pp. 3-37.

Oppenheim, M. (2015) “'It’s the Hardest Time of Year”: Why Domestic Violence Spikes Over Christmas'. New Statesman, December 22 ${ }^{\text {nd }}$. 
Orlikowski, W. J. (2007) 'Sociomaterial Practices: Exploring Technology at Work', Organization Studies, 28, pp. 1435-1448.

Parker, M. (2000) Organizational Culture and Identity. London: Sage.

Phelan, P. (1993) Unmarked. London: Routledge.

Pine, J. and Gilmour, J. (2011) The Experience Economy. Boston, MA: Harvard Business Review Press.

Salonen, A.S. (2016) 'The Christmas Celebration of Secondary Consumers: Observations from Food Banks in Finland'. Journal of Consumer Culture, 16, pp.870-886.

Schechner, R. (2006) Performance Studies, An Introduction. Abingdon: Routledge.

Schuyt, T. and Schuijt, J. (1998) 'Rituals and Rules: About Magic in Consultancy'. Journal of Organizational Change Management, 11, pp. 399-406,

Sheffield, H. (2016) 'How to Stop Christmas Waste and the Thousands of Tonnes Thrown Away Each Year'. The Independent, December 22 ${ }^{\text {nd }}$.

Stivers, R. (2004) 'The Role of Statistics in Management Magic'. Bulletin of Science, Technology \& Society, 24, pp. 99-106.

Strati, A. (1999) Organization and Aesthetics. London: Sage.

Styers, R. (2013) 'Magic and the Play of Power'. In, B. Otto and M. Stausberg (eds.) Defining Magic: A Reader. Abingdon: Routledge, pp. 255 - 262.

Tambiah, S. J. (2013) 'Form and Meaning of Magical Acts: A Point of View'. In, B. Otto and M. Stausberg (eds.) Defining Magic: A Reader. Abingdon: Routledge, pp. 178 - 186.

Thrift, N., (2004) 'Intensities of Feeling: Towards a Spatial Politics of Affect. Geografiska Annaler: Series B, Human Geography, 86, pp. 57-78.

Thrift, N. (2008) 'The Material Practices of Glamour', Journal of Cultural Economy, 1, pp. 9-21.

Turley, L. and Milliman, R. (2000) 'Atmospheric Effects on Shopping Behavior: A Review of the Experimental Evidence'. Journal of Business Research, 49, pp. 193-211.

Twitchell, J. B. (1996). Adcult USA: The Triumph of Advertising in American Culture. New York, NY: Columbia University Press.

Waldfogel, J. (2009) Scroogenomics: Why You Shouldn't Buy Presents for the Holidays. Princeton, NJ: Princeton University Press.

Waters, R. (2012) 'Learning the Tricks of a Magic Company', Financial Times On-Line, https://www.ft.com/content/a60f4534-41bb-11e1-a1bf-00144feab49a.

Warren, S. (2008) 'Empirical Challenges in Organizational Aesthetics Research: Towards a Sensual Methodology’. Organization Studies, 29, pp. 559-580. 
Weber, M. (2009) 'Science as a Vocation', in From Max Weber. London: Routledge.

Welsch, W. (1997) Undoing Aesthetics. London: Sage.

Williams, R. (1977) Marxism and Literature, Oxford: Oxford University Press.

Wittgenstein, L. (2009) Philosophical Investigations. Oxford: Blackwell.

Witz, A., C. Warhurst and D Nickson (2003). 'The Labour of Aesthetics and the Aesthetics of Organization', Organization, 10, pp. 33-54.

Wood, Z. (2017) 'Britons Borrow an Average $£ 452$ each on Credit Cards at Christmas’. The Guardian, December $27^{\text {th }}$.

Zaidman, N., Goldstein-Gidoni, O. and Nehemya, I. (2009) 'From Temples to Organizations: The Introduction and Packaging of Spirituality. Organization. 16, pp. 597-621.

\footnotetext{
${ }^{\mathrm{i}}$ http://www.retailresearch.org/shoppingforxmas.php

ii https://www.statista.com/topics/991/us-christmas-season/

iii https://www.independent.co.uk/life-style/christmas/christmas-adverts-2018-john-lewis-iceland-sainsburysheathrow-boots-a8634806.html

iv https://www.bakken.dk/world-santa-claus-congress-eng/

${ }^{v}$ https://www.youtube.com/watch?v=78OtNSzsRzQ
} 